\title{
Enhanced expression of Ang-(1-7) during pregnancy
}

\author{
K.B. Brosnihan ${ }^{1}$, \\ L.A.A. Neves ${ }^{1}$, \\ L. Anton ${ }^{1}$, J. Joyner ${ }^{1}$, \\ G. Valdes ${ }^{3}$ and D.C. Merrill ${ }^{2}$
}

\author{
${ }^{1}$ The Hypertension and Vascular Disease Center, and \\ ${ }^{2}$ Department of Obstetrics and Gynecology, \\ Wake Forest University School of Medicine, Winston-Salem, NC, USA \\ ${ }^{3}$ Departamento de Nefrologia, Universidad Católica de Chile, Santiago, Chile
}

\author{
Correspondence \\ K.B. Brosnihan \\ The Hypertension and Vascular \\ Disease Center \\ Wake Forest University \\ School of Medicine \\ Medical Center Boulevard \\ Winston-Salem, NC 27157-1032 \\ USA \\ Fax: +1-336-716-2456 \\ E-mail: bbrosnih@wfubmc.edu
}

Presented at the $\mathrm{V}$ International Symposium on Vasoactive Peptides, Ouro Preto, MG, Brazil,

February 12-14, 2004.

Received April 30, 2004 Accepted June 1, 2004

\begin{abstract}
Pregnancy is a physiological condition characterized by a progressive increase of the different components of the renin-angiotensin system (RAS). The physiological consequences of the stimulated RAS in normal pregnancy are incompletely understood, and even less understood is the question of how this system may be altered and contribute to the hypertensive disorders of pregnancy. Findings from our group have provided novel insights into how the RAS may contribute to the physiological condition of pregnancy by showing that pregnancy increases the expression of both the vasodilator heptapeptide of the RAS, angiotensin-(1-7) [Ang-(1-7)], and of a newly cloned angiotensin converting enzyme (ACE) homolog, ACE2, that shows high catalytic efficiency for Ang II metabolism to Ang-(1-7). The discovery of ACE2 adds a new dimension to the complexity of the RAS by providing a new arm that may counter-regulate the activity of the vasoconstrictor component, while amplifying the vasodilator component. The studies reviewed in this article demonstrate that Ang-(1-7) increases in plasma and urine of normal pregnant women. In preeclamptic subjects we showed that plasma Ang-(1-7) was suppressed as compared to the levels found in normal pregnancy. In addition, kidney and urinary levels of Ang-(1-7) were increased in pregnant rats coinciding with the enhanced detection and expression of ACE2. These findings support the concept that in normal pregnancy enhanced ACE2 may counteract the elevation in tissue and circulating Ang II by increasing the rate of conversion to Ang-(1-7). These findings provide a basis for the physiological role of Ang-(1-7) and ACE2 during pregnancy.
\end{abstract}

\section{Introduction}

Pregnancy is a physiological condition characterized by a progressive increase of the different components of the renin-angiotensin system(RAS). The physiological consequences of the stimulated RAS in normal pregnancy are incompletely understood, and even less under-
Key words

- Pregnancy

- Renin-angiotensin system

- Preeclampsia

- Angiotensin-(1-7)

.............. stood is the question of how this system may be altered and contribute to the hypertensive disorders of pregnancy. In normal pregnancy, estrogen and/or progesterone cause an overexpression of the RAS by augmenting both tissue and circulating levels of angiotensinogen $(1,2)$ and renin (3-7). During pregnancy, there is a large increase in plasma angiotensin- 
ogen due to stimulation of its hepatic synthesis by estrogen. In association with increased circulating estrogen, maternal prorenin and renin are also increased during pregnancy (8). Prorenin reaches a peak within 20 days after conception and remains high until parturition $(9,10)$. Plasma renin activity rises during the first few weeks of pregnancy and plasma angiotensin II (Ang II) increases in association with the rise of angiotensinogen and plasma renin activity during gestation $(11,12)$. Increased urinary and plasma aldosterone are found during pregnancy $(10,11)$. Pregnant women and animals are resistant to the pressor effects of Ang II (13-15) and they remain normotensive despite a 2-fold increase in Ang II, an event that has been associated with a down-regulation of the $\mathrm{AT}_{1}$ receptor $(12,16)$. In pregnant animals administration of angiotensin converting enzyme (ACE) inhibitors results in a decrease in blood pressure, demonstrating the tonic role of Ang II in blood pressure maintenance during pregnancy (17).

Despite the activation of the RAS during pregnancy, blood pressure is normal or decreased $(18,19)$. Why does an activation of the RAS not result in hypertension in normal pregnancy? Is the down-regulation of the $\mathrm{AT}_{1}$ receptor sufficient to account for the blood pressure changes? Or are there other components of the RAS that need to be considered? In pursuing this question, we discovered that estrogen shifts the pathways of formation of the angiotensin peptides in a tissue-specific manner, reducing formation of Ang II and augmenting the production of angiotensin-(1-7) [Ang-(1-7)] in Sprague Dawley and $m$ Ren 2 transgenic rats (20). Ang(1-7) acts as counter-regulator of the cardiovascular actions of Ang II by acting as a modulator of vascular tone (21). The vasodilatory actions of Ang-(1-7) have been reported for a number of vascular beds (22-28) and involve the release of nitric oxide, kinins, and prostaglandins (22-25). In addition, Ang-(1-7) was demonstrated to contribute to the anti-hypertensive actions of ACE inhibitors and $\mathrm{AT}_{1}$ receptor antagonists (2931). Prominent antihypertensive effects of Ang-(1-7) were demonstrated in experimental hypertensive models $(32,33)$. Local regional angiotensin peptide levels (kidney and adrenal) are modulated by the estrous cycle, resulting in an increase in Ang I and/or its product Ang-(1-7) during estrus (34,35).

The discovery of a new enzyme, ACE2, adds a potential new dimension to the complexity of the RAS. This enzyme shows approximately $42 \%$ homology with ACE (36, 37) but displays different biochemical activities from ACE. ACE2 is a carboxypeptidase that exhibits high catalytic efficiency to generate Ang-(1-7) at the same time that it inactivates the vasoconstrictor counterpart Ang II. ACE2 also cleaves one amino acid of Ang I to generate Ang-(1-9), which can be further processed into Ang-(1-7) by neprilysin and ACE (38). The catalytic efficiency of ACE2 in generating Ang-(1-7) from Ang II is almost 500 -fold greater than that for the conversion of Ang I to Ang-(1-9) and 10- to 600-fold higher than that of prolyl oligopeptidase and prolyl carboxypeptidase, respectively, to form Ang-(1-7) (38). ACE2 is insensitive to ACE inhibitors (captopril, lisinopril and enalapril) $(36,37)$, a fact suggesting that ACE2 may act to counter-regulate the activity of the vasoconstrictor components of the RAS. In light of these new findings, the question was raised if Ang-(17) and ACE2 could contribute to cardiovascular regulation in pregnancy.

Figure 1 is a schematic presentation of the action of the RAS and highlights potential places where pregnancy modulates components of the RAS.

\section{Human studies}

\section{Plasma Ang-(1-7) increases in normal human} pregnancy and decreases in preeclampsia

In normal human pregnancy we evaluated whether the known rise in plasma Ang 
II is counterbalanced by an increase in plasma Ang-(1-7) and whether a fall in plasma Ang(1-7) levels in preeclampsia may be a factor involved in the development of hypertension. Nulliparous preeclamptic patients and third trimester normotensive pregnant controls matched for parity, race, and gestational age were enrolled ( $\mathrm{N}=15$ /group). A nonpregnant group $(\mathrm{N}=15)$ was also included for comparison. Preeclampsia patients had no previous history of hypertension. Preeclampsia subjects had significant hypertension $(159 \pm 3 / 98 \pm 2 \mathrm{mmHg})$ and all had $>3+$ proteinuria. Plasma Ang I (176.4 \pm 57.1 vs $32.5 \pm 5.6 \mathrm{fmol} / \mathrm{ml}, \mathrm{P}<0.05)$, Ang II, and Ang-(1-7) were significantly elevated in normal pregnant women as compared to nonpregnant subjects (Figure 2). Plasma Ang$(1-7)$ was increased by $34 \%(\mathrm{P}<0.05)$ and plasma Ang II was increased by $50 \%(\mathrm{P}<$ $0.05)$. In preeclampsia subjects plasma Ang(1-7) was reduced $(14.2 \pm 2.3 \mathrm{fmol} / \mathrm{ml}, \mathrm{P}<$ 0.05 vs 3rd trimester of pregnancy); plasma Ang II was also reduced $(30.15 \pm 2.3$ vs 53.3 $\pm 10.1 \mathrm{fmol} / \mathrm{ml}$, preeclamptic $v s$ 3rd trimester normal pregnant, $\mathrm{P}<0.05$ ), but remained elevated compared to nonpregnant subjects $(20.1 \pm 1.5 \mathrm{fmol} / \mathrm{ml}, \mathrm{P}<0.05)$ and was $50 \%$ higher than plasma Ang-(1-7), suggesting that there is a shift in the balance of the peptides in preeclampsia. Other components of the RAS, with the exception of ACE, were reduced in preeclamptic subjects. Assessment of the relationship between Ang-(1-7) and blood pressure revealed a negative correlation of Ang-(1-7) with systolic $(\mathrm{r}=-0.4$, $\mathrm{P}<0.05)$ and diastolic $(\mathrm{r}=-0.5, \mathrm{P}<0.05)$ blood pressure. These data suggest a potential role for reduced production of Ang-(1-7) contributing to the elevated blood pressure. These studies confirm that the RAS is activated in the third trimester of normal pregnancy, including an increase in plasma Ang(1-7) levels. In preeclampsia, the decreased levels of plasma Ang-(1-7) in the presence of persistent elevated plasma Ang II are consistent with the development of hypertension.

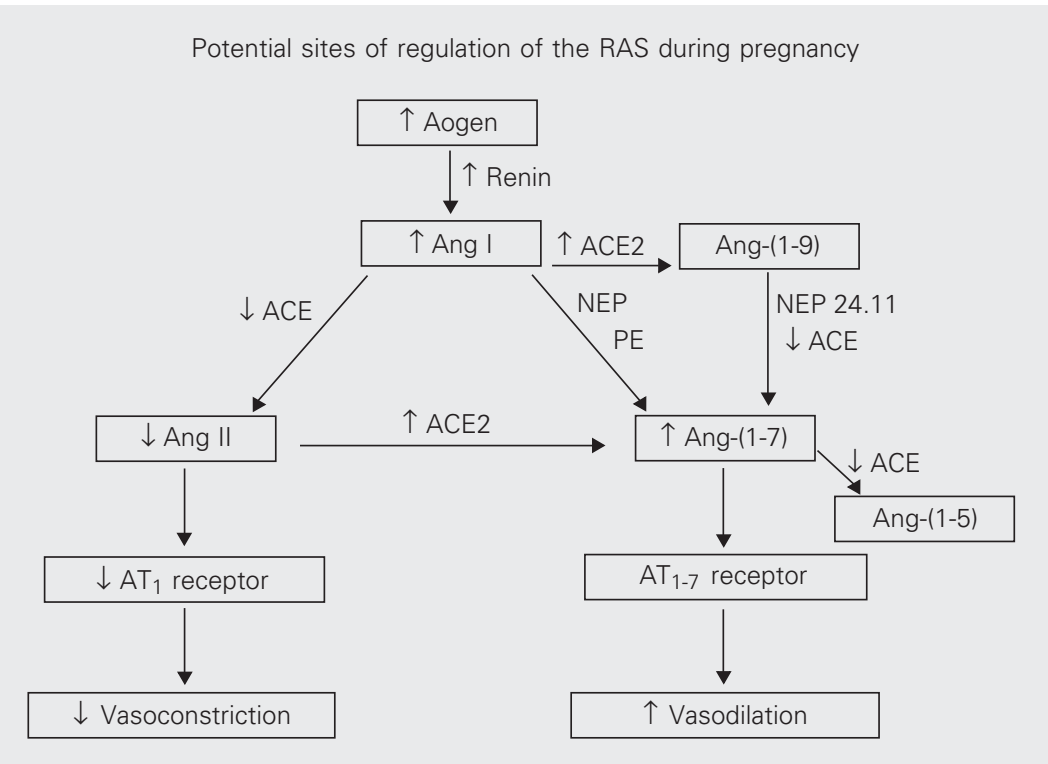

Figure 1. Schematic presentation of the renin-angiotensin system. Arrows indicate points of up- or down-regulation of RAS components. $\mathrm{ACE}=$ angiotensin converting enzyme: ACE2 = angiotensin converting enzyme 2; Ang $\mathrm{I}=$ angiotensin $\mathrm{I}$; Ang-(1-7) = angiotensin(1-7); Aogen = angiotensinogen; NEP = neutral endopeptidases; NEP 24.11 = neprilysin; PE $=$ prolyl endopeptidase.

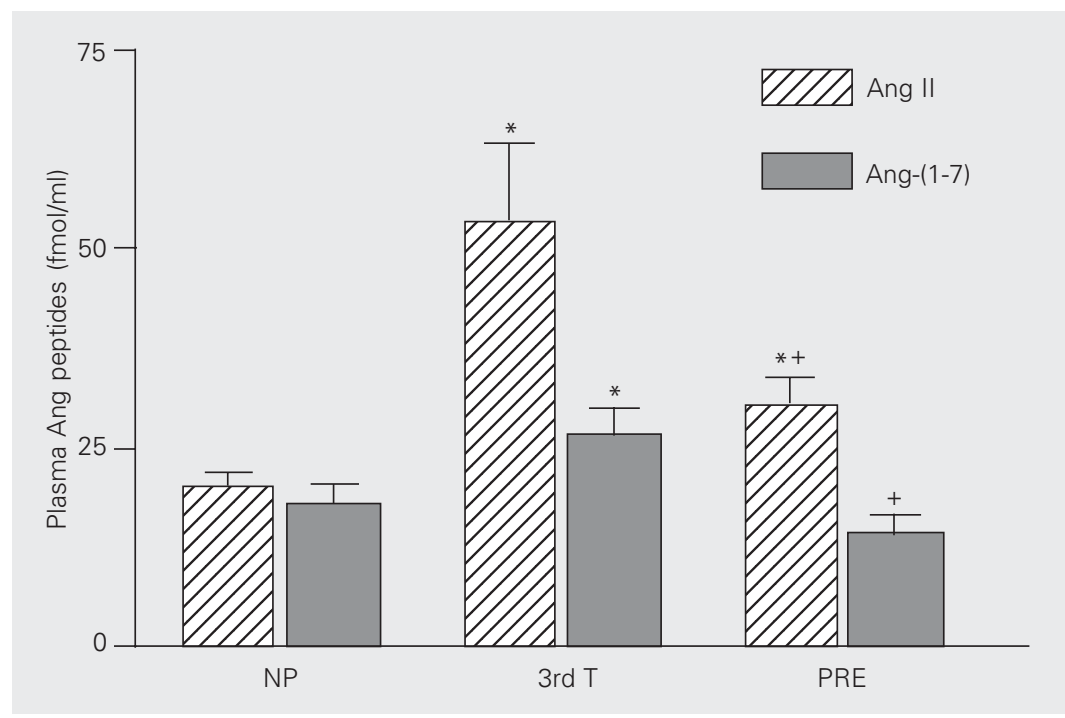

Figure 2. Plasma levels of angiotensin II (Ang II) and Ang-(1-7) in nonpregnant (NP) and pregnant women at the 3rd trimester of pregnancy (3rd T) and in preeclamptic subjects (PRE). Data are reported as means \pm SEM for 15 subjects in each group. Data are adapted from Merrill et al. (39). ${ }^{*} P<0.05$ compared to NP; ${ }^{+P}<0.05$ compared to 3rd T (Student $t$ test) 


\section{Urinary Ang-(1-7) increases throughout normal human pregnancy}

In these studies, the 24-h urinary excretion of Ang-(1-7) and Ang II was evaluated during the ovulatory menstrual cycle and during singleton normotensive pregnancies

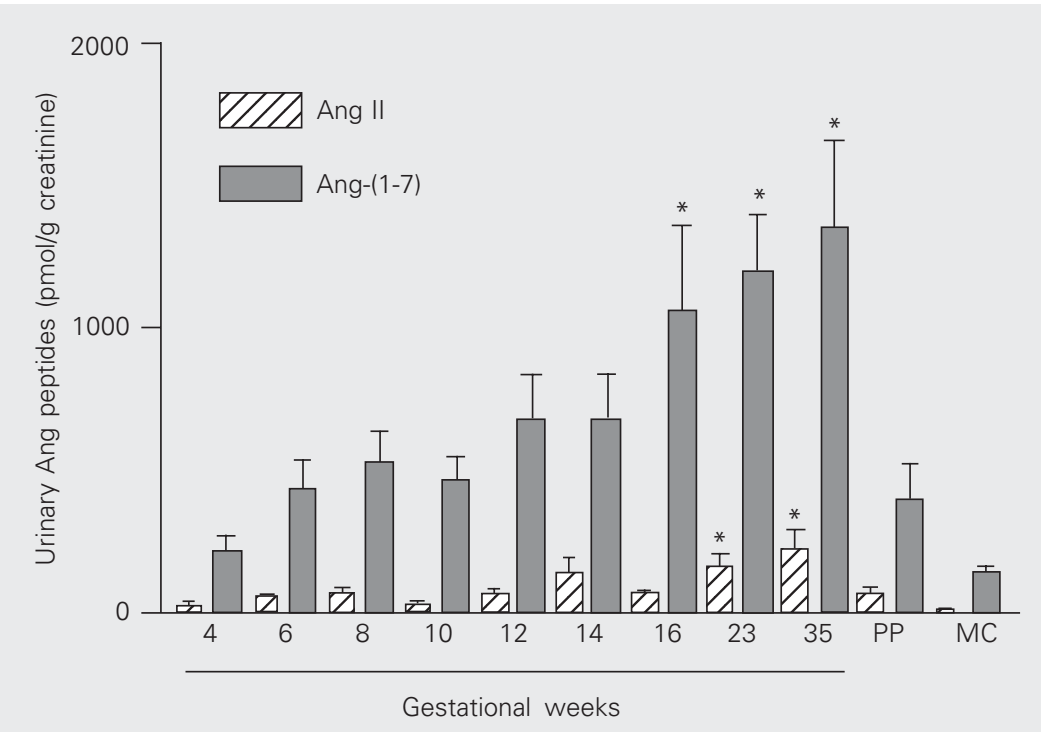

Figure 3. Urinary excretion of angiotensin II (Ang II) and Ang-(1-7) during gestation, lactation $(\mathrm{PP})$, and menstrual cycle $(\mathrm{MC})$. Data are reported as means \pm SEM for $\mathrm{N}=10$ during gestation, $N=10$ during lactation and $N=9$ during the menstrual cycle. Although not indicated, all values of urinary Ang II and Ang-(1-7) were significantly different from those found during the menstrual cycle. Data are adapted from Valdes et al. (40). ${ }^{*} P<0.05$ compared to day 4 of gestation (Student $t$-test).

Table 1. Basal characterization of virgin female and 19th day pregnant rats.

\begin{tabular}{|c|c|c|}
\hline & $\begin{array}{l}\text { Virgin female rat } \\
\qquad(N=13)\end{array}$ & $\begin{array}{l}\text { 19th day pregnant rat } \\
\qquad(\mathrm{N}=18)\end{array}$ \\
\hline Maternal body weight (g) & $251 \pm 11$ & $332 \pm 5^{*}$ \\
\hline Litter size (No.) & - & $12.6 \pm 0.4$ \\
\hline Fetus weight (g) & - & $1.43 \pm 0.01$ \\
\hline Urinary flow (ml/24 h) & $15 \pm 0.9$ & $22.0 \pm 1.2^{*}$ \\
\hline Creatinine excretion ( $\mu \mathrm{mol} 24 \mathrm{~h}^{-1} \mathrm{~g}^{-1}$ ) & $0.35 \pm 0.03$ & $0.36 \pm 0.02$ \\
\hline 17ß-estradiol (pM) & $22.6 \pm 1.6$ & $101.3 \pm 14.8^{*}$ \\
\hline Angiotensinogen (nM) & $278 \pm 32$ & $436 \pm 27^{*}$ \\
\hline $\operatorname{PRC}\left(\mathrm{nmol} \mathrm{I} \mathrm{l}^{-1} \mathrm{~min}^{-1}\right)$ & $4.25 \pm 0.7$ & $15.8 \pm 3.2^{*}$ \\
\hline Serum ACE $\left(\mu \mathrm{mol} \min ^{-1} \mathrm{l}^{-1}\right)$ & $107 \pm 5.7$ & $80 \pm 3.5^{*}$ \\
\hline Plasma Ang I (pM) & $29.4 \pm 3.1$ & $32.7 \pm 3.6$ \\
\hline Plasma Ang II (pM) & $24.9 \pm 2.0$ & $19.6 \pm 1.6$ \\
\hline Plasma Ang-(1-7) (pM) & $32.1 \pm 5.2$ & $46.9 \pm 9.8$ \\
\hline
\end{tabular}

Data are reported as mean \pm SEM. $A C E=$ angiotensin converting enzyme; $\mathrm{PRC}=$ plasma renin concentration. ${ }^{*} P<0.05$ compared to virgin rats (Student $t$-test). and their subsequent lactation. Two groups of normotensive, non-proteinuric women were studied: group 1 consisted of 9 cycling women with previous normal obstetrical histories and group 2 consisted of 10 women with a normal pregnancy and previous normal obstetrical history. No significant differences in urinary Ang-(1-7) were observed between the follicular or luteal phase of the normal menstrual cycle (data not shown). There was a progressive rise of urinary Ang(1-7) throughout normal human gestation, attaining levels that were 10 -fold greater than those observed during the normal menstrual cycle (Figure 3). Urinary Ang II showed a similar pattern, reaching levels that were 25-fold higher than the values observed during the menstrual cycle. At 35 weeks of gestation, urinary Ang-(1-7) was the predominant angiotensin peptide in the urine, reaching levels that were 6-fold higher than Ang II. The urinary excretion levels may reflect local kidney production of peptides and thus during pregnancy the elevated renal Ang-(1-7) may play a role in the vasodilatory adaptations of mid and late human pregnancy.

\section{Animal studies}

In order to better dissect the RAS during pregnancy, studies were conducted on an animal model. Pregnant rats were evaluated at late gestation (19th day) and virgin female rats were evaluated during the diestrus phase of the estrous cycle.

\section{Kidney concentration and urinary excretion rate of Ang-(1-7), Ang II and Ang I in virgin and pregnant rats}

Table 1 shows the basal characterization of both virgin and pregnant rats. Virgin animals were at the diestrus phase of the estrous cycle as indicated by cytology and resting plasma 17ß-estradiol concentration, which were nearly 5 -fold lower than those found in 
pregnant animals. Urinary flow was significantly increased during late pregnancy $(\mathrm{P}<$ $0.05)$ without a change in creatinine excretion. Pregnancy was associated with significant increases in plasma angiotensinogen (57\%) and plasma renin concentration (271\%). Serum ACE activity was decreased by $20 \%$ in pregnant animals. In contrast to the human pregnant subjects, there was no significant change in plasma concentration of Ang I, Ang II and Ang (1-7) at the 19th day of pregnancy.

Twenty-four hour urinary excretion of the angiotensin peptides was significantly increased in pregnant animals (Figure 4), reaching levels that were increased by $93 \%$ (Ang I), 44\% (Ang II) and 60\% [Ang-(1-7)] of values found in virgin rats. Kidney Ang I and Ang-(1-7) concentrations were significantly increased in pregnant animals as compared to virgin females. The Ang I and Ang(1-7) concentrations were increased by 7 and 5-fold, respectively $(\mathrm{P}<0.05)$. There was no significant change in kidney Ang II concentration of pregnant and virgin females. These studies provide evidence that urinary excretion of angiotensin peptides reflects local kidney content of angiotensin during pregnancy.

\section{Renal immunocytochemical distribution of Ang-(1-7) and ACE2 during pregnancy}

In these studies we determined the renal immunocytochemical distribution of Ang(1-7) and ACE2 in kidneys of virgin and 19day pregnant Sprague Dawley rats. Rats were sacrificed on the 19th day of pregnancy and tissues were examined for renal immunocytochemical distribution using a polyclonal antibody to Ang-(1-7) or a monoclonal antibody to ACE2 (Figure 5). Ang-(1-7) immunostaining was predominantly localized to the inner cortex and outer medulla and was found in proximal and distal tubules. There was no staining in the glomerulus. ACE2 immunostaining was also visualized predomi-

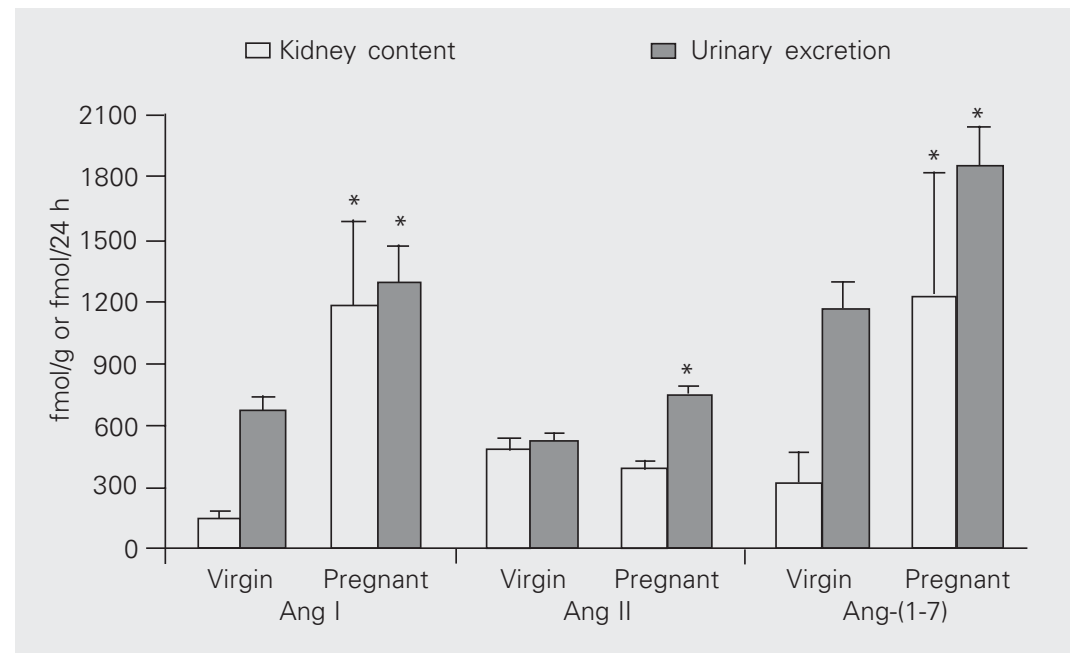

Figure 4. Kidney and urinary levels of angiotensin I (Ang I), Ang II, and Ang-(1-7) in virgin rats at diestrus and in pregnant rats at late gestation. Data are reported as means \pm SEM for $\mathrm{N}$ $=14$ (urine) and $N=9$ (kidney) virgin rats and $N=19$ (urine) and $N=10$ (kidney) pregnant rats. Data are adapted from Neves et al. (41). ${ }^{*} \mathrm{P}<0.05$ compared to virgin rats (Student $t$ test)
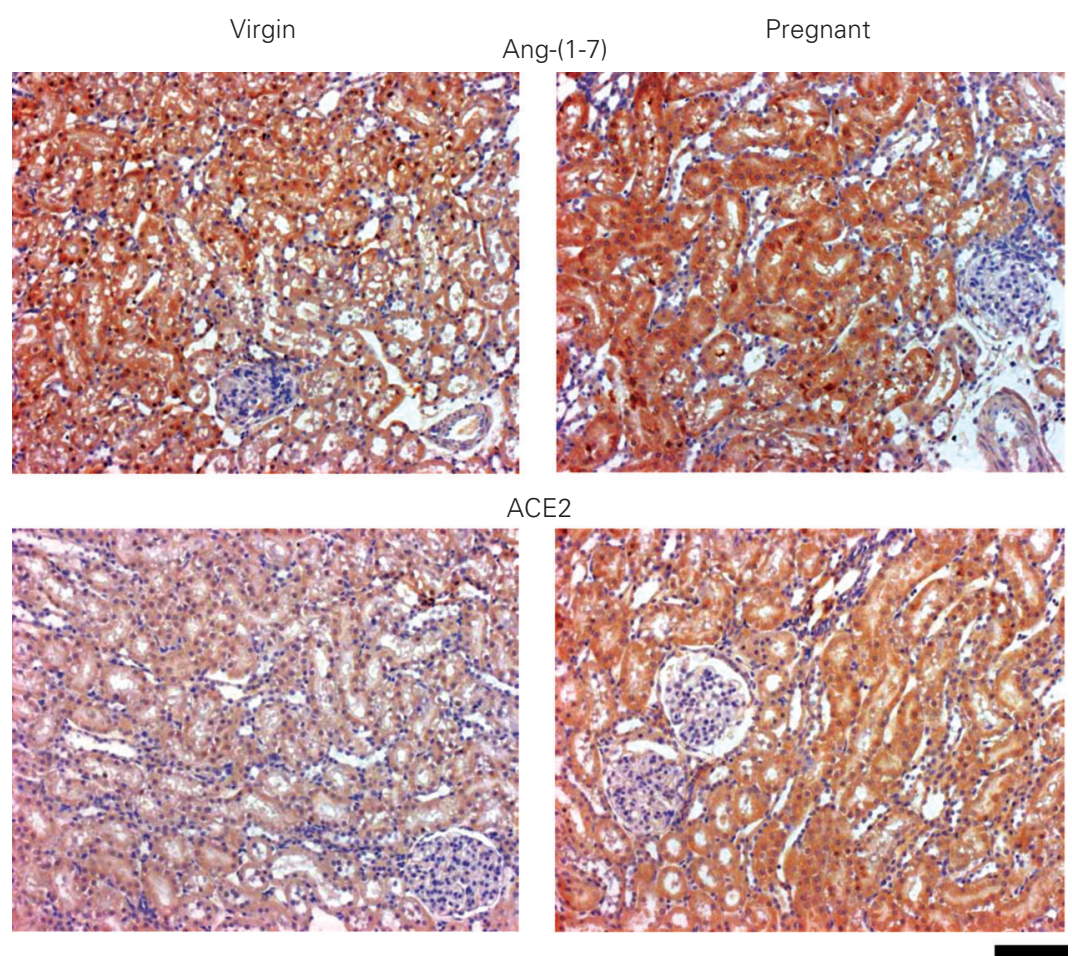

$100 \mu \mathrm{m}$

Figure 5. Immunocytochemical distribution of angiotensin converting enzyme 2 (ACE2) and Ang-(1-7) in the kidney of virgin and pregnant rats. Data are adapted from Brosnihan et al. (42). Bar $=100 \mu \mathrm{m}$ for all panels. 
nantly in the tubules of the inner cortex/outer medulla region of both virgin and pregnant rats and was not found in the glomerulus. Analysis of the Ang-(1-7) (33 \pm 0.6 vs $21 \pm$ 1.6 arbitrary units, $\mathrm{P}<0.05$ pregnant $v s$ virgin) and ACE2 $(25 \pm 4.0$ vs $11 \pm 0.9$ arbitrary units, $\mathrm{P}<0.05$ pregnant $v s$ virgin) immunostaining revealed that kidneys from pregnant rats had a more intense staining compared to virgin females. The similar localization of ACE2 and Ang-(1-7) suggests that ACE2 may play a role in the renal production of Ang-(1-7) in pregnancy.

\section{Pregnancy enhances the vasodilator response} to Ang-(1-7) in rat mesenteric arteries

In order to evaluate a functional response of Ang-(1-7) during pregnancy, the Ang-(17) vasodilator effect was assessed in mesen-

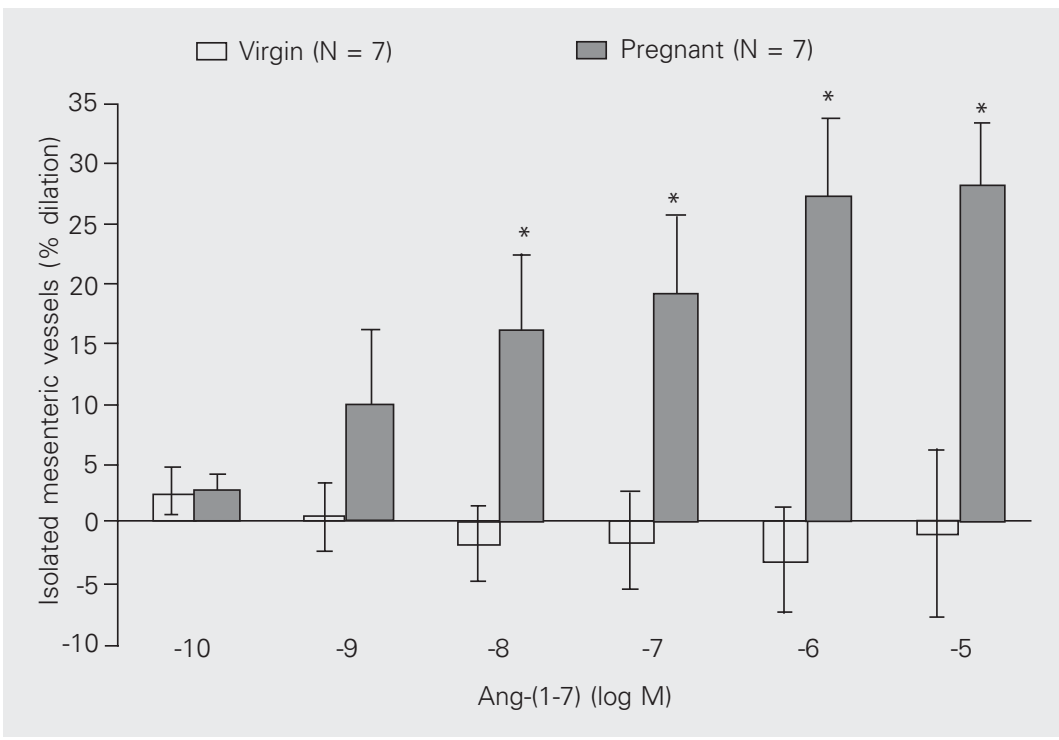

Figure 6. Dose response to angiotensin-(1-7) [Ang-(1-7)] in isolated mesenteric vessels from virgin rats at diestrus and from pregnant rats at late gestation. Data are reported as means \pm SEM for 7 virgin rats and 7 pregnant rats. Data are adapted from Neves et al. (41). ${ }^{*} \mathrm{P}<0.05$ for virgin vs pregnant rats (one-way ANOVA followed by Newman-Keuls). teric resistance vessels from pregnant and virgin female rats. Mesenteric arteries (230$290 \mu \mathrm{m})$ from 19-day-old pregnant Sprague Dawley rats and age-matched virgin females were mounted in a pressurized myograph system. Ang-(1-7) concentration-dependent response curves $\left(10^{-10}\right.$ to $\left.10^{-5} \mathrm{M}\right)$ were determined in arteries pre-constricted with endothelin-1 $\left(10^{-7} \mathrm{M}\right)$. Addition of progressively higher concentrations of Ang-(1-7) (10 $10^{-10}$ to $\left.10^{-5} \mathrm{M}\right)$ had no effect on mesenteric vessels isolated from virgin female rats at the diestrus phase of the estrous cycle (Figure 6). In contrast, in pregnant animals Ang-(1-7) $\left(10^{-10}\right.$ to $\left.10^{-5} \mathrm{M}\right)$ caused significant dilation of the mesenteric vessels $(\mathrm{P}=0.05)$. Ang-(17) reached a maximum plateau at $10^{-6} \mathrm{M}$ and displayed an $\mathrm{EC}_{50}$ of $2.7 \mathrm{nM}$. Pretreatment of the vessels with the specific Ang-(1-7) receptor antagonist $\mathrm{D}-\mathrm{Ala}^{7}$ completely blocked the Ang-(1-7)-induced dilation in pregnant rats (data not shown, $\mathrm{P}<0.05$ ), providing further evidence that pregnancy increases the vascular endothelial response to Ang-(1-7).

These studies have demonstrated that there is enhanced Ang-(1-7) expression during pregnancy. In normal human pregnancy, plasma Ang-(1-7) is increased, whereas in preeclampsia there is a decrease in plasma Ang-(1-7). In both humans and rats, pregnancy is accompanied by increased urinary excretion of Ang-(1-7), which in the rat is reflective of the increased renal concentration of Ang-(1-7). In the kidney, Ang-(1-7) and ACE2 are similarly distributed and there is an enhanced distribution of both in pregnancy. Finally, the increased Ang-(1-7) vasodilation in mesentery resistance vessels in pregnancy supports the concept that Ang-(17) may be an important contributor to blood pressure regulation in pregnancy. 


\section{References}

1. Nasjletti A \& Masson GMC (1972). Studies on angiotensinogen formation in a liver perfusion system. Circulation Research, 30 (Suppl II): 187-202.

2. Tewksbury DA (1990). Angiotensinogen - biochemistry and molecular biology. In: Laragh JH \& Brenner BM (Editors), Hypertension: Pathophysiology, Diagnosis and Management. Raven Press, New York, 1197-1216.

3. Chen Y, Naftilan AJ \& Oparil S (1992). Androgen-dependent angiotensinogen and renin messenger RNA expression in hypertensive rats. Hypertension, 19: 456-463.

4. Rubattu S, Quimby FW \& Sealey JE (1991). Tissue renin and prorenin increase in female cats during the reproductive cycle without commensurate changes in plasma, amniotic or ovarian follicular fluid. Journal of Hypertension, 9: 525-535.

5. Glorioso N, Atlas SA, Laragh JH, Jewelewicz R \& Sealey JE (1986). Prorenin in high concentrations in human ovarian follicular fluid. Science, 233: 1422-1424.

6. Howard RB, Pucell AG, Bumpus FM \& Husain A (1988). Rat ovarian renin: Characterization and changes during the estrous cycle. Endocrinology, 123: 2331-2340.

7. Oelkers WKH (1996). Effects of estrogens and progestogens on the renin-aldosterone system and blood pressure. Steroids, 61: 166171.

8. Alhenc-Gelas F \& Menard J (1986). The Renin-Angiotensin System in Pregnancy and Parturition. Year Book Medical Publishers, Inc., Chicago, IL, USA, 25-33.

9. August $P$, Lenz $T$, Ales $K L$, Druzin $M L$, Edersheim TG, Hutson JM, Muller FB, Laragh JH \& Sealey JE (1990). Longitudinal study of the renin-angiotensin-aldosterone system in hypertensive pregnant women: deviations related to the development of superimposed preeclampsia. American Journal of Obstetrics and Gynecology, 163: 1612-1621.

10. August P \& Sealey JE (1990). The renin-angiotensin system in normal and hypertensive pregnancy and in ovarian function. In: Laragh JH \& Brenner BM (Editors), Hypertension: Pathophysiology, Diagnosis and Management. Raven Press, New York, 1761-1778.

11. Brown MA, Wang J \& Whitworth JA (1997). The renin-angiotensinaldosterone system in preeclampsia. Clinical and Experimental $\mathrm{Hy}$ pertension, 19: 713-726.

12. Baker PN, Pipkin FB \& Symonds EM (1990). Platelet angiotensin II binding and plasma renin concentration, plasma renin substrate and plasma angiotensin II in human pregnancy. Clinical Science, 79: 403-408.

13. Baker PN, Pipkin FB \& Symonds EM (1992). Comparative study of platelet angiotensin II binding and the angiotensin II sensitivity test as predictors of pregnancy-induced hypertension. Clinical Science, 83: 89-95.

14. Gant NF, Daley GL, Chand S, Whalley PJ \& MacDonald PC (1973). A study of angiotensin II pressor response throughout primigravid pregnancy. Journal of Clinical Investigation, 52: 2682-2689.

15. Chesley LC, Talledo E, Bohler CS \& Zuspan FP (1965). Vascular reactivity to angiotensin II and norepinephrine in pregnant and nonpregnant women. American Journal of Obstetrics and Gynecology, 91: 837-842

16. Baker PN, Broughton PF \& Symonds EM (1992). Longitudinal study of platelet angiotenin II binding in human pregnancy. Clincal Science, 82: 377-381.

17. Ferris TF \& Weir EK (1983). Effect of captopril on uterine blood flow and prostaglandin $\mathrm{E}$ synthesis in the pregnant rabbit. Journal of
Clinical Investigation, 71: 809-815.

18. Barron WM, Murphy MB \& Lindheimer MD (1990). Management of hypertension during pregnancy. In: Laragh JH \& Brenner BM (Editors), Hypertension: Pathophysiology, Diagnosis and Management. Raven Press, New York, 1809-1827.

19. Chesley LC (1999). Chesley's Hypertensive Disorders in Pregnancy. Appleton \& Lange, Stamford, CT, USA.

20. Li P, Ferrario CM, Ganten D \& Brosnihan KB (1997). Chronic estrogen treatment in female transgenic (mRen2)27 hypertensive rats augments endothelium-derived nitric oxide release. American Journal of Hypertension, 10: 662-670.

21. Ferrario CM, Chappell MC, Tallant EA, Brosnihan KB \& Diz DI (1997). Counterregulatory actions of angiotensin-(1-7). Hypertension, 30: 535-541.

22. Gorelik G, Carbini LA \& Scicli AG (1998). Angiotensin 1-7 induces bradykinin-mediated relaxation in porcine coronary artery. Journal of Pharmacology and Experimental Therapeutics, 286: 403-410.

23. Brosnihan KB, Li P \& Ferrario CM (1996). Angiotensin-(1-7) dilates canine coronary arteries through kinins and nitric oxide. Hypertension, 27: 523-528.

24. Oliveira MA, Fortes ZB, Santos RA, Kosla MC \& De C (1999). Synergistic effect of angiotensin-(1-7) on bradykinin arteriolar dilation in vivo. Peptides, 20: 1195-1201.

25. Osei SY, Ahima RS, Minkes RK, Weaver JP, Khosla MC \& Kadowitz PJ (1993). Differential responses to angiotensin-(1-7) in the feline mesenteric and hindquarters vascular beds. European Journal of Pharmacology, 234: 35-42.

26. Meng W \& Busija DW (1993). Comparative effects of angiotensin(1-7) and angiotensin II on piglet pial arterioles. Stroke, 24: 20412045.

27. Feterik K, Smith L \& Katusic ZS (2001). Angiotensin-(1-7) causes endothelium-dependent relaxation in canine middle cerebral artery. Brain Research, 873: 75-82.

28. Forster C \& Le Tran Y (1997). Angiotensin-(1-7) and the rat aorta: modulation by the endothelium. Journal of Cardiovascular Pharmacology, 30: 676-682.

29. Kohara K, Brosnihan KB \& Ferrario CM (1993). Angiotensin-(1-7) in the spontaneously hypertensive rat. Peptides, 14: 883-891.

30. Santos RAS, Brosnihan KB, Jacobsen DW, DiCorleto PE \& Ferrario CM (1992). Production of angiotensin-(1-7) by human vascular endothelium. Hypertension, 19 (Suppl II): II-56-II-61.

31. Campbell DJ, Kladis A \& Duncan AM (1994). Effects of converting enzyme inhibitors on angiotensin and bradykinin peptides. Hypertension, 23: 439-449.

32. Moriguchi A, Tallant EA, Matsumura K, Reilly TM, Walton H, Ganten D \& Ferrario CM (1995). Opposing actions of angiotensin-(1-7) and angiotensin II in the brain of transgenic hypertensive rats. Hypertension, 25: 1260-1265.

33. Nakamoto H, Ferrario CM, Fuller SB, Robaczwski DL, Winicov E \& Dean RH (1995). Angiotensin-(1-7) and nitric oxide interaction in renovascular hypertension. Hypertension, 25: 796-802.

34. Campbell DJ (1997). Differential regulation of angiotensin peptides in plasma and kidney: effects of adrenalectomy and estrogen treatment. Clinical and Experimental Hypertension, 19: 687-698.

35. Senanayake PS, Smeby RR, Martins AS, Moriguchi A, Kumagai $H$, Ganten D \& Brosnihan KB (1998). Adrenal, kidney, and heart angiotensins in female murine Ren-2 transfected hypertensive rats. Peptides, 19: 1685-1694.

36. Donoghue M, Hsieh F, Baronas E et al. (2000). A novel angiotensin- 
converting enzyme-related carboxypeptidase (ACE2) converts angiotensin I to angiotensin 1-9. Circulation Research, 87: e1-e9.

37. Tipnis SR, Hooper NM, Hyde R, Karran E, Christie G \& Turner AJ (2000). A human homolog of angiotensin-converting enzyme. Cloning and functional expression as a captopril insensitive carboxypeptidase. Journal of Biological Chemistry, 275: 33238-33243.

38. Vickers C, Hales P, Kaushik V et al. (2002). Hydrolysis of biological peptides by human angiotensin-converting enzyme-related carboxypeptidase. Journal of Biological Chemistry, 277: 14838-14843.

39. Merrill DC, Karoly M, Chen K, Ferrario CM \& Brosnihan KB (2002). Angiotensin-(1-7) in normal and preeclamptic pregnancy. Endocrine, 18: $239-245$.

40. Valdes G, Germain AM, Corthorn J, Berrios C, Foradori AC, Ferrario
CM \& Brosnihan KB (2001). Urinary vasodilator and vasoconstrictor angiotensins during menstrual cycle, pregnancy, and lactation. Endocrine, 16: 117-122

41. Neves LAA, Williams AF, Averill DB, Ferrario CM, Walkup MP \& Brosnihan KB (2003). Pregnancy enhances the angiotensin (Ang)-(17) vasodilator response in mesenteric arteries and increases the renal concentration and urinary excretion of Ang-(1-7). Endocrinology, 14: 3338-3343.

42. Brosnihan KB, Neves LA, Joyner J, Averill DB, Chappell MC, Sarao R, Penninger J \& Ferrario CM (2003). Enhanced renal immunocytochemical expression of ANG-(1-7) and ACE2 during pregnancy. $\mathrm{Hy}$ pertension, 42: 749-753. 